O $\quad R \quad$ I $\quad G \quad I \quad N \quad A \quad L$

A $\quad$ R $\quad$ T I I C L

\title{
Impact of magnetic resonance imaging on preoperative planning for breast cancer surgery
}

\section{Y Law 羅 旭 \\ Polly SY Cheung 張淑儀 \\ Silvia Lau 劉淑思 \\ Gladys G Lo 羅吳美英}

Key words

Breast neoplasms; Magnetic resonance imaging; Preoperative care

Hong Kong Med J 2013;19:294-9 DOI: $10.12809 / \mathrm{hkmj} 133928$

Department of Surgery, Queen Mary

Hospital, Pokfulam, Hong Kong Y Law, MB, BS, MRCs Hong Kong Sanatorium and Hospital, Happy Valley, Hong Kong: Breast Care Centre

PSY Cheung, FCSHK, FHKAM (Surgery) Medical Physics and Research Department

S Lau, BSc, MSc, MPH

Department of Diagnostic and Interventional Radiology

GG Lo, FHKCR, FHKAM (Radiology)

Correspondence to: Dr PSY Cheung

Email: pollyc@pca.hk
Objectives To review the impact of preoperative breast magnetic resonance imaging on the management of planned surgery, and the appropriateness of any resulting alterations.

Design Retrospective review.

Setting A private hospital in Hong Kong.

Patients For the 147 consecutive biopsy-proven breast cancer patients who underwent preoperative magnetic resonance imaging to determine tumour extent undergoing operation by a single surgeon between 1 January 2006 and 31 December 2009, the impact of magnetic resonance imaging findings was reviewed in terms of management alterations and their appropriateness.

Results The most common indication for breast magnetic resonance imaging was the presence of multiple indeterminate shadows on ultrasound scans ( $53 \%$ ), followed by ill-defined border of the main tumour on ultrasound scans (19\%). In $66 \%$ (97 out of 147) of the patients, the extent of the operation was upgraded. Upgrading entailed: lumpectomy to wider lumpectomy (23 out of 97), lumpectomy to mastectomy (47 out of 97), lumpectomy to bilateral lumpectomy (15 out of 97), and other (12 out of 97). Mostly, these management changes were because magnetic resonance imaging showed more extensive disease $(n=29)$, additional cancer foci $(n=39)$, or contralateral disease $(n=24)$. In five instances, upgrading was due to patient preference. In $34 \%$ (50 out of 147) of the patients, there was no change in the planned operation. Regarding 97 of the patients having altered management, in 12 the changes were considered inappropriately extensive (due to false-positive magnetic resonance imaging findings). In terms of magnetic resonance imaging detection of more extensive, multifocal, multicentric, or contralateral disease, the false-positive rate was $13 \%$ and false-negative rate $7 \%$. Corresponding rates for sensitivity and specificity were $95 \%$ and $81 \%$, using the final pathology as the gold standard.

Conclusions Preoperative magnetic resonance imaging had a clinically significant and mostly correct impact on management plans. Magnetic resonance imaging should be included as part of the preoperative investigation in patients planned for breastconserving surgery, in whom there are doubts about the extent of the tumours based on conventional assessment.

\footnotetext{
New knowledge added by this study

Magnetic resonance imaging (MRI) significantly impacted preoperative breast cancer surgery planning.

- Most alterations in planned management were considered appropriate.

- MRI demonstrated high sensitivity and moderate specificity in detecting additional cancer foci.

- Preoperative MRI should be considered in patients with suspected additional disease foci or indeterminate tumour margins, in addition to conventional imaging by mammography and ultrasonography.
} 


\section{Introduction}

The selection of optimal treatment for breast cancer patients, namely breast-conservative treatment (BCT) or mastectomy, is often difficult. Apart from mammography and ultrasound, breast magnetic resonance imaging (MRI) is emerging as a useful preoperative adjunct to assist surgeons facing this decision. ${ }^{1,2}$ Thus, MRI provides additional information on the precise extent of disease, including index tumour size, location, and margin; the lesion-tobreast-size ratio; invasion to nipple or chest wall; and whether there was multifocal (additional foci in the same quadrant of index tumour), multicentric (additional foci in a different quadrant of index tumour), or contralateral disease. Not uncommonly, mammography and ultrasonography miss additional ipsilateral foci (reported frequency, 11-57\%) and contralateral foci (reported frequency up to $10 \%)^{7-10}$ All of these observations are important in preoperative planning.

The use of MRI was not without controversy, however. Several reviews by Houssami et $\mathrm{al}^{11-13}$ argued that consistently, MRIs changed surgical management, usually from breast conservation to more radical surgery, but there was no evidence of associated improved surgical outcomes or prognosis. More importantly, the recent randomised COMICE trial ${ }^{14}$ concluded that MRI might be unnecessary as a means of reducing reoperation rates.

Asian patients are well known to have higher breast densities than their counterparts, ${ }^{15,16}$ making differentiation of normal from abnormal breast tissue more difficult and challenging. The usefulness of preoperative breast MRI in our locality is still unknown. This is the first large series to address the usefulness of MRI in an Asian population. In particular, the present study aimed to review the impact of preoperative breast MRI on altering management and the appropriateness of such alterations.

\section{Methods}

All consecutive biopsy-proven breast cancer patients managed by a single surgeon from 1 January 2006 to 31 December 2009 at the Hong Kong Sanatorium and Hospital were reviewed. Patients who had undergone preoperative MRI were selected for analysis.

All the patients had undergone standard preoperative workup, including triple assessment consisting of (1) clinical examination, (2) imaging using mammography and ultrasonography, and (3) cytohistological diagnosis by fine-needle aspiration or core-needle biopsy. The primary tumour was confirmed by cytology or biopsy. Patients with an index tumour deemed suitable for breast-conserving surgery but features suspicious for multicentric disease were selected to undergo breast MRIs.

\section{磁共振成像對乳腺癌手術術前規劃的影響}

目的回顧術前磁共振對於乳腺癌手術規劃的影響, 並探討 因此而產生任何規劃變化的恰當性。

設計 回顧分析。

安排 香港一間私家醫院。

患者 2006 年1月 1 日至2009年12月31日期間由一名外科醫 生進行術前磁共振成像以找出腫瘤範圍的連續147名 活檢證實的乳腺癌患者, 回顧術前磁共振對於乳腺癌 手術規劃的影響及恰當性。

結果進行乳腺磁共振成像最常見的原因是在超聲掃描上 出現多個不確定的陰影（53\%），其次是超聲掃 描上的主要腫瘤界限不清（19\%）。結果發現 $66 \%$ （99/147）患者的手術範圍升級, 包括：乳房腫瘤切 除擴至更大範圍（23/97）、乳房腫瘤切除術擴至乳 房切除術 (47/97) 、單側乳房腫瘤切除術擴至雙側 （15/97）及其他（12/97）。大多數情況下, 這些手 術規劃的改變主要是因為磁共振成像顯示更廣泛的病 灶 $(n=29)$ 、病灶出現附加病變 $(n=39)$ 或發現對 側病變 $(n=24)$ 。五例是因應患者要求而進行手術 範圍升級。有34\%（50/147）患者的手術規劃並無改 變。97名手術規劃有變的患者中, 12例被認為是不適 當的擴大變化（因磁共振成像上的假陽性結果）。使 用磁共振成像檢測更廣泛、更多焦點、更多中心性的 或對側病變的乳腺癌, 其假陽性率為 $13 \%$, 假陰性率 為7\%。如按最終病理結果作標準, 磁共振成像的敏感 性和特異性分別為 $95 \%$ 和 $81 \%$ 。

結論 術前磁共振成像對於手術規劃有很大的臨床意義和影 響。對於計劃進行保乳手術但又對評估腫瘤範圍的傳 統技術有懷疑的病人來説, 應進行術前磁共振。

Details of these indications are listed in Table 1.

A 3T Siemens MR Scanner (MAGNETOM Tim Trio) was used with a 4-channel-phased array coil. The protocol for breast MRI entailed imaging as follows:

TABLE I. Indications for magnetic resonance imaging

\begin{tabular}{lc}
\hline Indication* & $\begin{array}{c}\text { No. (\%) of } \\
\text { patients (n=147) }\end{array}$ \\
\hline Nodular breast on clinical examination & $11(7)$ \\
MMG showed multiple pleomorphic microcalcification & $6(4)$ \\
MMG showed dense tissue & $3(2)$ \\
USG showed ill-defined border & $28(19)$ \\
USG showed multiple indeterminate shadows & $78(53)$ \\
Suspicion for multi-tumour on core-needle biopsy & $3(2)$ \\
Discordance between clinical, imaging, and histological finding & $9(6)$ \\
To locate occult primary focus with positive axillary LN & $1(1)$ \\
To search for residual tumour after excisional biopsy & $7(5)$ \\
Previous injection mammoplasty & $1(1)$ \\
\hline
\end{tabular}

* MMG denotes mammography, USG ultrasound, and LN lymph node 
- $\quad$ Sagittal T1-weighted

- Sagittal fat-saturated T2-weighted

- Axial fat-saturated T2-weighted

- Axial single-shot echo-planar diffusion-weighted imaging with $b$ value of 0 and $1000 \mathrm{~s} / \mathrm{mm}^{2}$

- Axial dynamic contrast-enhanced T1-weighted with fat-saturated (1-min temporal resolution) $\mathrm{x}$ 5 mins

- Delayed axial fat-saturated T1-weighted high resolution with contrast

- Delayed sagittal fat-saturated T1-weighted high resolution with contrast

All images were reported by three independent radiologists with 4 to 13 years of experience in breast MRI interpretation. The breast lesions were evaluated on dynamic contrast-enhanced scans according to their morphological and dynamic curve interpretation criteria, as described by the American College of Radiology Breast Imaging Reporting and Data System-MRI (BI-RADS-MRI). Regular radiology meetings were conducted to obtain a consensus if there was disagreement among the radiologists. A formal radiological report was made available to the surgeon before each operation.

Second-look ultrasounds and biopsies were repeated for any suspicious (BI-RADS 4) or diagnostic (BI-RADS 5) additional lesions identified by MRI. If ultrasonography failed to identify the lesion, MRIguided needle biopsy was performed; patients could also opt for open biopsy in the same setting of cancer surgery. The type of operation would then be decided according to the size, location, and number of cancer foci together with the patient's breast volume.

All operations with breast conservation entailed frozen section control, meaning an additional margin to be excised if intra-operative frozen section showed a close or touching margin. Specimens were examined by standard paraffin sections and the pathology was reported.

This was a retrospective cohort study on 147 consecutive patients who had preoperative MRIs before planned breast-conserving surgery. After the MRI, any changes in operative extent and the appropriateness of the preplanned procedure were recorded.

Any new lesion identified by MRI in addition to the main tumour was compared with final specimen pathology. Any BI-RADS 1-3 lesions were regarded as MRI negative, while BI-RADS 4 or 5 lesions were viewed as MRI positive. The final pathology of the corresponding lesion was reviewed and compared with the MRI categorisation. Pathologists were blinded to the MRI findings. False-positive and false-negative rates in term of detection of more extensive, multifocal/multicentric or contralateral disease were calculated based on the final specimen pathology.

\section{Results}

A total of 659 breast cancer patients were managed in the relevant time period, out of which, 147 had preoperative MRIs and hence were included in the current study. As shown in Table 1, the most frequent indication for breast MRI was multiple indeterminate shadows on ultrasound scans (53\%) followed by illdefined borders around the main tumour (19\%). The median age of these 147 patients was 47 (range, $30-70)$ years. All were female and $77 \%(n=113)$ were premenopausal; 91\% $(n=134)$ were Asians and the remainder Caucasians.

In $66 \%$ (97 out of 147 ) of these patients, the extent of the previously planned operation was upgraded from lumpectomy to a wider lumpectomy (23 out of 97), mastectomy (47 out of 97), bilateral lumpectomy (15 out of 97), and other (12 out of 97) [Fig 1]. Such upgrading was mainly based on MRI findings showing more extensive disease $(n=29)$, additional cancer focus/foci $(n=39)$, and contralateral disease $(n=24)$. In five patients, the decision was based on patient preference for mastectomy even after detailed counselling that the MRI showed additional benign lesions only. Examples are shown in Figures 2 to 4 . In $34 \%$ (50 out of 147) of these patients, there was no change in planned operation.

Regarding 97 of these patients for whom management was altered, in 12 the change was considered inappropriately extensive due to falsepositive MRI findings. Thus, in 85 (88\%) out of 97 patients, the altered management was regarded as appropriate (Fig 1).

In all, 89 patients underwent breast-conserving surgery (BCT) while 58 underwent mastectomy. Despite MRI use, 18\% (16 out of 89 ) of those undergoing BCT underwent re-excision (Fig 1), because of close in-situ tumour margins in the final paraffin section (ie resection margin of less than 5 $\mathrm{mm}$ ). None of these patients had surgery in which the margins were found to be positive for in-situ or invasive cancer.

In terms of MRI detection of more extensive, multifocal/multicentric, or contralateral disease, the false-positive rate was $13 \%$ and the false-negative rate was $7 \%$, with a corresponding sensitivity of $95 \%$ and specificity of $81 \%$ (Table 2 ).

\section{Discussion}

In addition to clinical evaluation, conventional triple assessment uses mammography and ultrasonography as imaging modalities. The accuracy of such imaging in determining the extent of operations on breast cancers may be compromised in younger patients with dense breasts or multiple indeterminate shadows on ultrasound scans. Breast MRI provides additional information on tumour size, location, 


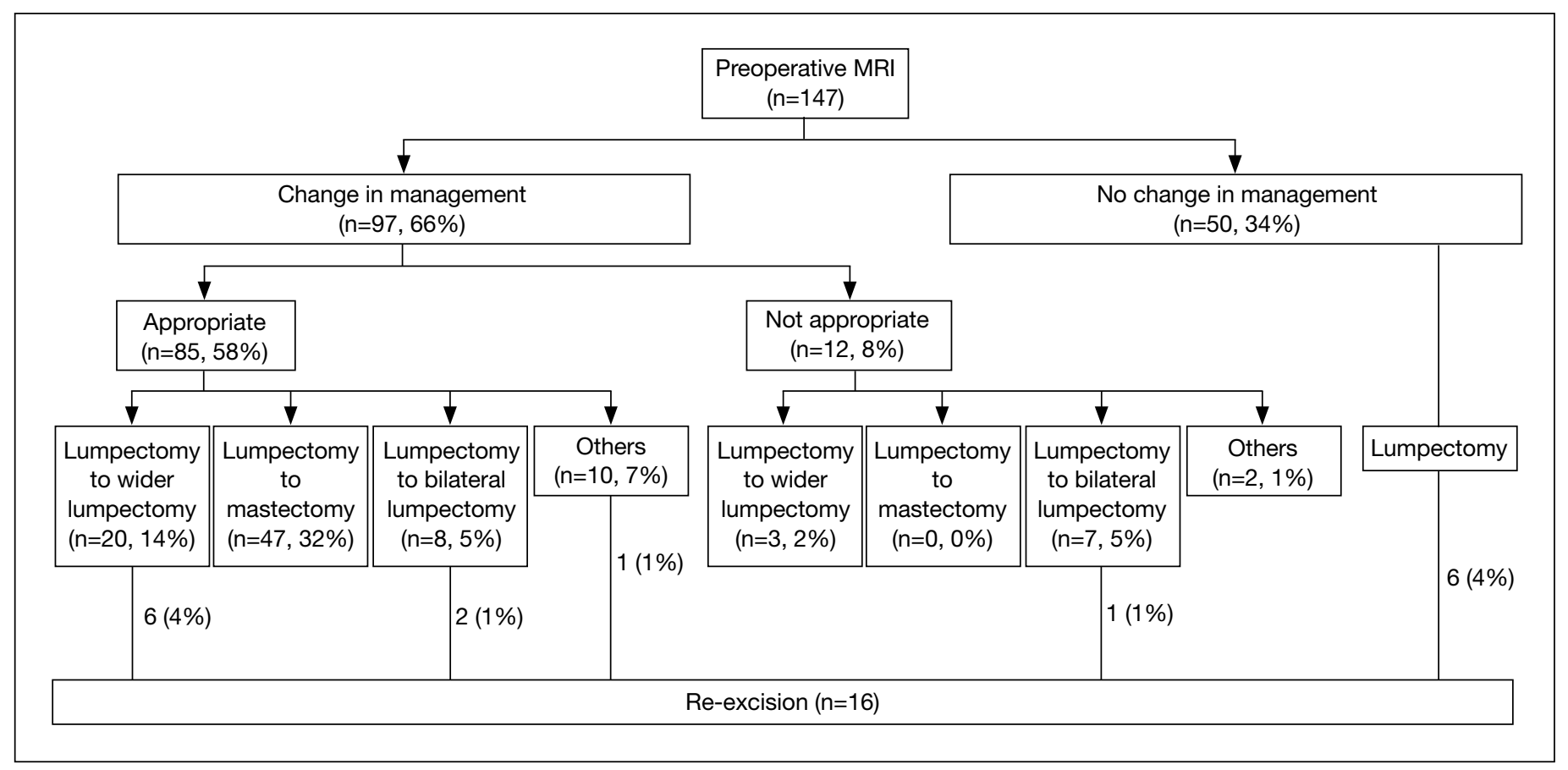

FIG I. Patient flowchart

MRI denotes magnetic resonance imaging

TABLE 2. $2 \times 2$ Table for calculation of sensitivity and specificity

\begin{tabular}{lccc}
\hline \multirow{2}{*}{$\begin{array}{l}\text { Magnetic resonance } \\
\text { imaging }\end{array}$} & \multicolumn{3}{c}{ Final pathology } \\
\cline { 2 - 4 } & Positive & Negative & Total \\
\hline Positive & 80 & 12 & 92 \\
Negative & 4 & 51 & 55 \\
Total & $\mathbf{8 4}$ & $\mathbf{6 3}$ & $\mathbf{1 4 7}$ \\
\hline
\end{tabular}

border, multifocality, multicentricity, and whether there was contralateral disease. This should translate into a theoretical benefit in preoperative surgical planning for patients being considered for BCT. ${ }^{1,2,17}$

Contrast-enhanced breast MRI has been demonstrated to outperform mammography and ultrasonography in evaluating index tumour size as well as in detecting additional ipsilateral and contralateral tumours, and shows otherwise undetected multifocal/multicentric and contralateral cancers. Meta-analyses showed that in about $11 \%$ of patients having planned ipsilateral surgical treatment, MRI-detected additional cancers resulted in changed management, ${ }^{11}$ and 3 to $4 \%$ of patients also had MRIdetected contralateral cancers. ${ }^{12} \mathrm{~A}$ recently published meta-analysis confirmed these data, showing similar percentages ( $12 \%$ and $3 \%$, respectively) based on a larger number of studies. ${ }^{18}$

Asian breast density is known to be greater than in Caucasians, which is evident on both physical examination and imaging. ${ }^{15,16}$ Moreover, MRI further enhances the distinction between normal and diseased breast tissue. This is the first large series describing such MRI findings in Asians.

Given the theoretical benefit of MRI in preoperative planning, previous papers identified two main study end-points; the first was a shortterm benefit via reducing the re-excision rate ${ }^{19-26}$; the second was long-term benefit resulting in improved disease recurrence rate and survival. ${ }^{27}$ In view of disease recurrence and mortality being so rare in the modern era, most studies were unable to provide data on the second end-point. Thus, only data on alteration in surgical extent/planning are available.

Similar to others, our study demonstrated alteration in the extent of surgery in a significant number of patients after undergoing breast MRI. Whether this translates into improvements in recurrence and/or survival rates will be revealed by future data.

Several review articles published by Houssami et $\mathrm{al}^{11-13}$ strongly maintained that breast MRI would only cause more patients suitable for BCT to undergo more radical surgery without evidence to indicate improved survival. However, missed multicentric disease may be responsible for future recurrences. Studies have also shown that MRI measurement of tumour size was closest to histological findings. One of the aims of breast MRI was to reduce re-excision rates. This rate was $18 \%(n=89)$ in our cohort, which 


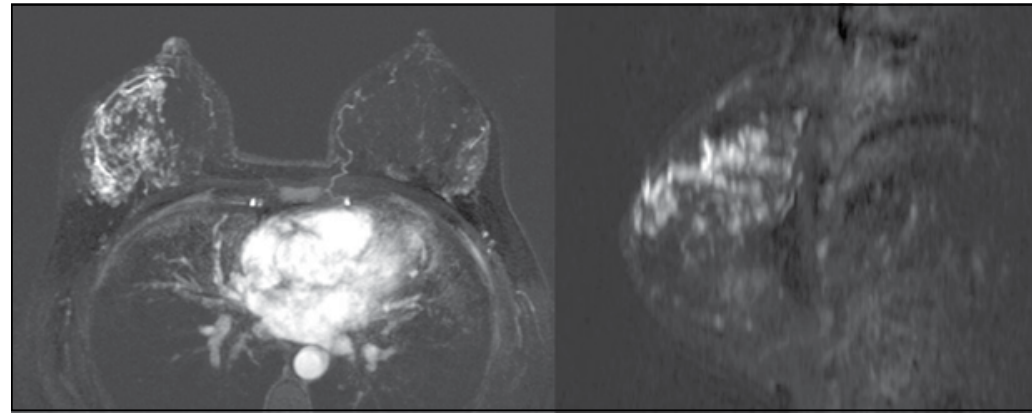

FIG 2. The right breast lump of a patient was found to be much more extensive than originally thought, requiring subsequent mastectomy

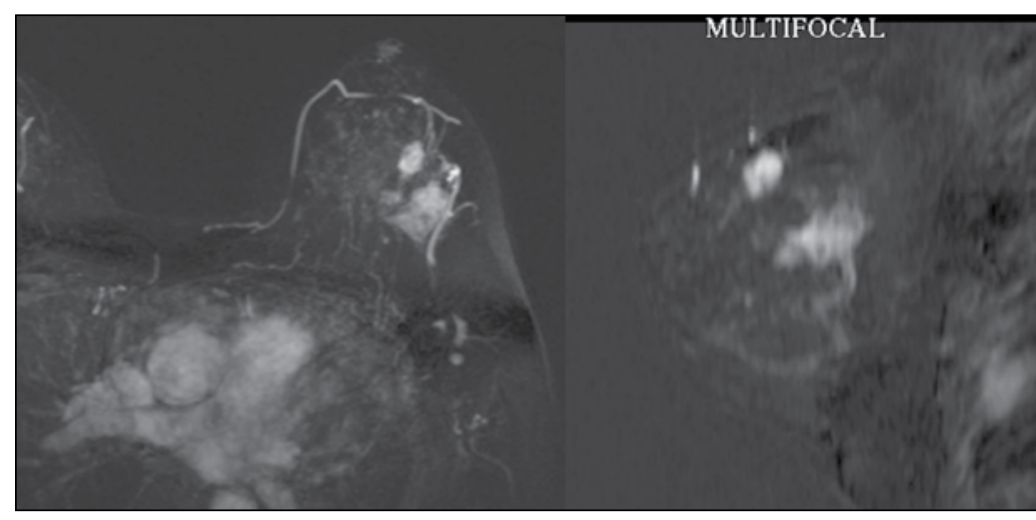

FIG 3. A second focus was found in a patient's magnetic resonance imaging. A wider lumpectomy was considered necessary

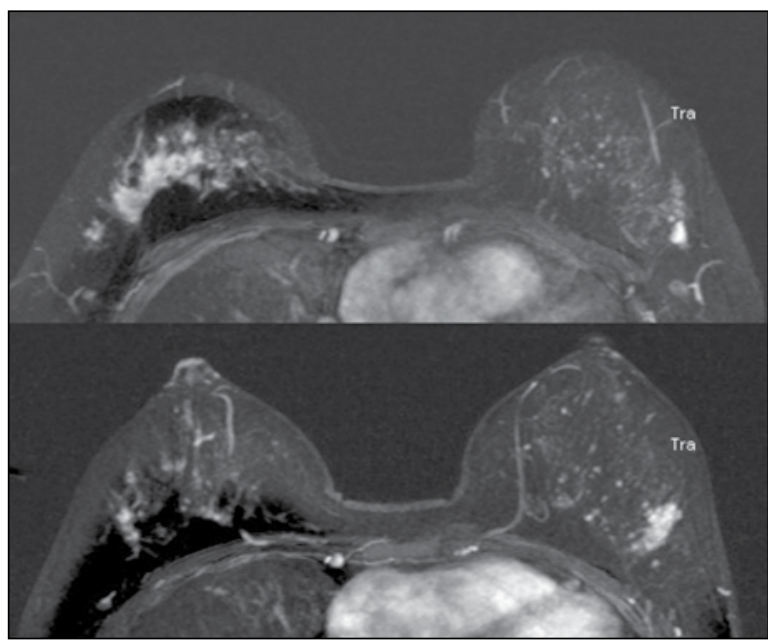

FIG 4. In additional to extensive right breast involvement, a contralateral left breast focus was incidentally found; this patient underwent bilateral mastectomy was similar to rates quoted worldwide. ${ }^{14}$ If the whole cohort $(n=147)$ is considered as a group, only $11 \%$ underwent repeated operations; in other words, $89 \%$ could achieve a single-stage procedure, which was a satisfactory result in this group of complex patients.

Despite there being no current evidence to support breast MRI on a routine basis as shown in our patient cohort, it may nevertheless be useful under special circumstances, which include dense breasts with dubious shadows on ultrasound, tumours masked by dense mammography findings, or discordance in triple assessment. Other indications include occult primary tumour in a patient presenting with axillary lymphadenopathy, to differentiate scar tissue or foreign body granuloma from tumour, and previous breast augmentation.

Breast MRI consistently demonstrated high sensitivity and moderate specificity for the detection of additional foci. ${ }^{28}$ Our study used the final histology of the surgical specimen as the gold standard for calculation of false-positive and -negative rates, as well as sensitivity and specificity. The false-positive rate should be reliable. However the false-negative rate needs cautious interpretation, because a large portion of patients with negative MRI findings will not undergo more extensive operations and hence histological proof of the negative MRI may be lacking. However, none of our patients had an early recurrence on follow-up (within 4-7 years).

The pathology of all four cases with falsenegative findings (Table 2) were reviewed. Three of them had ductal carcinoma in situ (DCIS), while the remaining one had DCIS with a small focus of invasive cancer. They were offered operations despite the MRI showing benign lesions, because screening mammography showed suspicious microcalcifications. Therefore although MRI provides invaluable additional information, it cannot replace mammography for detecting DCIS, which usually presents as micro-calcification.

\section{Conclusion}

Preoperative MRI in selected cases had a significant and mostly correct impact on management plans, and should be included as part of preoperative staging in complex cases indeterminate for breast-conserving cancer surgery.

\section{References}

1. Kuhl C. The current status of breast MR imaging. Part I. Choice of technique, image interpretation, diagnostic accuracy, and transfer to clinical practice. Radiology 2007;244:356-78. cross ref

2. Kuhl CK. Current status of breast MR imaging. Part 2. 4. Holland R, Veling SH, Mravunac M, Hendriks JH. Histologic
Clinical applications. Radiology 2007;244:672-91. cross ref

3. Anastassiades O, lakovou E, Stavridou N, Gogas J, Karameris A. Multicentricity in breast cancer. A study of 366 cases. Am J Clin Pathol 1993;99:238-43. 
multifocality of Tis, T1-2 breast carcinomas. Implications for clinical trials of breast-conserving surgery. Cancer 1985;56:979-90. cross ref

5. Schwartz GF, Patchefsky AS, Feig SA, Shaber GS, Schwartz $A B$. Clinically occult breast cancer. Multicentricity and implications for treatment. Ann Surg 1980;191:8-12. cross ref

6. Schwartz GF, Patchesfsky AS, Feig SA, Shaber GS, Schwartz AB. Multicentricity of non-palpable breast cancer. Cancer 1980;45:2913-6. cross ref

7. Heron DE, Komarnicky LT, Hyslop T, Schwartz GF, Mansfield CM. Bilateral breast carcinoma: risk factors and outcomes for patients with synchronous and metachronous disease. Cancer 2000;88:2739-50. cross ref

8. Poggi MM, Danforth DN, Sciuto LC, et al. Eighteen-year results in the treatment of early breast carcinoma with mastectomy versus breast conservation therapy: the National Cancer Institute Randomized Trial. Cancer 2003;98:697702. cross ref

9. Samant RS, Olivotto IA, Jackson JS, Mates D. Diagnosis of metachronous contralateral breast cancer. Breast J 2001; 7:405-10. cross ref

10. Veronesi U, Cascinelli N, Mariani L, et al. Twenty-year follow-up of a randomized study comparing breastconserving surgery with radical mastectomy for early breast cancer. N Engl J Med 2002;347:1227-32. cross ref

11. Houssami N, Ciatto S, Macaskill P, et al. Accuracy and surgical impact of magnetic resonance imaging in breast cancer staging: systematic review and meta-analysis in detection of multifocal and multicentric cancer. J Clin Oncol 2008;26:3248-58. cross ref

12. Brennan ME, Houssami N, Lord S, et al. Magnetic resonance imaging screening of the contralateral breast in women with newly diagnosed breast cancer: systematic review and meta-analysis of incremental cancer detection and impact on surgical management. J Clin Oncol 2009;27:56409. cross ref

13. Houssami N, Hayes DF. Review of preoperative magnetic resonance imaging (MRI) in breast cancer: should MRI be performed on all women with newly diagnosed, early stage breast cancer? CA Cancer J Clin 2009;59:290-302. cross ref

14. Turnbull L, Brown S, Harvey I, et al. Comparative effectiveness of MRI in breast cancer (COMICE) trial: a randomised controlled trial. Lancet 2010;375:56371. cross ref

15. del Carmen MG, Halpern EF, Kopans DB, et al. Mammographic breast density and race. AJR Am J Roentgenol 2007;188:1147-50. cross ref

16. El-Bastawissi AY, White E, Mandelson MT, Taplin S. Variation in mammographic breast density by race. Ann Epidemiol 2001;11:257-63. cross ref
17. Weinstein S, Rosen M. Breast MR imaging: current indications and advanced imaging techniques. Radiol Clin North Am 2010;48:1013-42. cross ref

18. Plana MN, Carreira C, Muriel A, et al. Magnetic resonance imaging in the preoperative assessment of patients with primary breast cancer: systematic review of diagnostic accuracy and meta-analysis. Eur Radiol 2012;22:2638. cross ref

19. Schiller DE, Le LW, Cho BC, Youngson BJ, McCready DR. Factors associated with negative margins of lumpectomy specimen: potential use in selecting patients for intraoperative radiotherapy. Ann Surg Oncol 2008;15:83342. cross ref

20. Bagley $\mathrm{FH}$. The role of magnetic resonance imaging mammography in the surgical management of the index breast cancer. Arch Surg 2004;139:380-3; discussion 383. cross ref

21. Schell AM, Rosenkranz K, Lewis PJ. Role of breast MRI in the preoperative evaluation of patients with newly diagnosed breast cancer. AJR Am J Roentgenol 2009;192:143844. cross ref

22. Braun M, Pölcher M, Schrading S, et al. Influence of preoperative MRI on the surgical management of patients with operable breast cancer. Breast Cancer Res Treat 2008;111:179-87. cross ref

23. Angarita FA, Acuna SA, Fonseca A, Crystal P, Escallon J. Impact of preoperative breast MRIs on timing of surgery and type of intervention in newly diagnosed breast cancer patients. Ann Surg Oncol 2010;17 Suppl 3:273-9. cross ref

24. Bilimoria KY, Cambic A, Hansen NM, Bethke KP. Evaluating the impact of preoperative breast magnetic resonance imaging on the surgical management of newly diagnosed breast cancers. Arch Surg 2007;142:441-5; discussion 445-7. cross ref

25. Mann RM, Loo CE, Wobbes $T$, et al. The impact of preoperative breast MRI on the re-excision rate in invasive lobular carcinoma of the breast. Breast Cancer Res Treat 2010;119:415-22. cross ref

26. Kneeshaw PJ, Turnbull LW, Smith A, Drew PJ. Dynamic contrast enhanced magnetic resonance imaging aids the surgical management of invasive lobular breast cancer. Eur J Surg Oncol 2003;29:32-7. cross ref

27. Hwang N, Schiller DE, Crystal P, Maki E, McCready DR. Magnetic resonance imaging in the planning of initial lumpectomy for invasive breast carcinoma: its effect on ipsilateral breast tumor recurrence after breast-conservation therapy. Ann Surg Oncol 2009;16:3000-9. cross ref

28. Lo GG, Ai V, Chan JK, et al. Diffusion-weighted magnetic resonance imaging of breast lesions: first experiences at $3 \mathrm{~T}$. J Comput Assist Tomogr 2009;33:63-9. cross ref 